Article

\title{
Kinetic study and kinetic parameters of lipase-catalyzed glycerolysis of sardine oil in a homogeneous medium
}

\author{
Ángela García Solaesa, María Teresa Sanz*, Sagrario Beltrán, Rodrigo Melgosa \\ Department of Biotechnology and Food Science (Chemical Engineering Section), University of Burgos, Burgos 09001, Spain
}

\section{A R T I C L E I N F O}

Article history:

Received 18 November 2015

Accepted 4 January 2016

Published 5 April 2016

\section{Keywords:}

Lipase

Glycerolysis

Tert-butanol

Mass transfer

Kinetic model

\begin{abstract}
A B S T R A C T
The production of polyunsaturated fatty acids (PUFAs) concentrates by enzymatic catalysis has gained interest due to their stereospecificity and the milder conditions employed compared to the use of inorganic catalysts. The enzymatic glycerolysis of sardine oil by Lipozyme ${ }^{\circledR} 435$ to get PUFA concentrates in the forms of di- and monoacylglycerols (DAGs, MAGs) in an optimized amount of tert-butanol as the organic solvent was studied. First, mass transfer limitation of the reaction system was analyzed. The effects of different operating variables such as lipase loading, temperature and feed composition were investigated. A semi-empirical kinetic model based on the reversible elementary reactions of glycerolysis and hydrolysis of the glycerides was employed to correlate the experimental kinetic data. A molar ratio glycerol:oil of 3:1 was the optimum, which produced more than $84 \mathrm{wt} \%$ of MAG at $323 \mathrm{~K}$. A comparison with other glycerolysis systems was performed using MAG yield, reaction rate and significance of kinetic parameters.
\end{abstract}

(C) 2016, Dalian Institute of Chemical Physics, Chinese Academy of Sciences. Published by Elsevier B.V. All rights reserved.

\section{Introduction}

Fish oil is rich in omega-3 (n-3) polyunsaturated fatty acids (PUFAs) such as eicosapentaenoic acid (EPA) and docosahexaenoic acid. The health benefits of $n-3$ fatty acids have been widely established in the literature [1-3]. Among the different types of lipid derivatives containing PUFA concentrates, MAG and DAG have good bioavailability [4,5]. In addition, MAG or its mixtures with DAG account for $75 \%$ of worldwide emulsifier production [6]. The process currently used in industry to obtain MAG is glycerolysis using an inorganic alkaline catalyst at high temperature (493-533 K). This method has several disadvantages such as it gives a dark color and burnt taste as well as high energy consumption. Furthermore, chemical glycerolysis is not suitable for producing MAG rich in PUFA due to oxidization problems. Enzymatic glycerolysis is an attractive al- ternative for the production of MAG rich in PUFA since the reaction can be carried out under mild conditions [7] and structured products are obtained.

The immiscibility of the reactants, glycerol and oil leads to mass transfer limitation in the glycerolysis of oils. Different approaches have been used in the literature to improve the contact between the reactants and hence reduce mass transfer limitation. Lipase-catalyzed glycerolysis has been carried out in different reaction media such as organic solvents [8], compressed fluids [9], and ionic liquids [10] in order to improve the mass transfer. Recently, the uses of different surfactants to increase the interfacial area [11] and ultrasound irradiation [12] have also been proposed to reduce mass transfer limitation.

This paper is part of a wider project for the optimization of MAG production by enzymatic glycerolysis of sardine oil. First, different tert-alcohols were evaluated as the solvent used to

* Corresponding author. Tel: +34-947 258810. Fax: +34-947-258831; E-mail: tersanz@ubu.es 
create a homogeneous phase [13]. Tertiary alcohols enhance the enzyme activity and accelerate the reaction rate as compared to the solvent-free system [14]. In a previous work, tert-pentanol was selected as the solvent and the effect of the glycerol:oil molar ratio was evaluated for its effect on kinetic behavior and MAG yield. The glycerolysis product was subsequently fractionated by a two-step molecular distillation to obtain a concentrated product of MAG and DAG rich in PUFA [15]. In this work, a different tertiary alcohol, tert-butanol (TB) was used as the solvent. TB has been used in different glycerolysis systems of vegetable oils such as olive oil [16,17], palm oil [18], camellia oil [19] and sunflower oil [8,20].

The main objective of this work is to present a detailed kinetic study of enzymatic glycerolysis of refined sardine oil in TB as the solvent catalyzed by a commercial lipase Lipozyme ${ }^{\circledR}$ 435. The amount of TB added to create a monophasic system has been optimized based on liquid-liquid equilibrium (LLE) data previously determined [13]. This value was compared with the amount of TB added to other glycerolysis systems. The results in terms of MAG and DAG yields were compared with literature data reported for different type of oils and related to the high activity of the lipase for short and medium chain length fatty acids.

First, the external and internal mass transfer resistances were analyzed in the heterogeneous system of the immobilized lipase. Mass transfer limitation can play an important role in the reaction rate. However, in most glycerolysis studies reported in the literature, no mass transfer studies were performed.

Mathematical models are needed to predict and optimize the industrial process. However, not many works in the literatures deal with the kinetic modeling of glycerolysis. One of the first works was carried out by Moquin et al. [9]. In that work, the kinetics of the non-catalyzed glycerolysis of soybean oil in supercritical $\mathrm{CO}_{2}$ medium were correlated by a sequence of reversible reactions to take into account the parallel hydrolysis reaction. The same model was used by Valerio et al. [11] in the kinetic study of solvent-free lipase-catalyzed glycerolysis of olive oil by Novozym 435 with Triton X-100 as surfactant. Although glycerolysis and hydrolysis reactions were proposed, no information on the experimental FFA (free fatty acid) production and rate of change of glycerol were provided and only the TAG (triacylglycerols), MAG and DAG concentrations were used in the fitting procedure to obtain the kinetic parameters. The mechanism of glycerolysis and hydrolysis of pure POP (1,3-palmitin-2-olein) by Rhizopus arrhizus lipase was studied by Tan et al. [21] by including hydrolysis, esterification and isomerization of MAG and DAG. Cheirsilp et al. [22] proposed a Ping-Pong Bi Bi model that focused on the kinetics of the hydrolysis and esterification steps involved in the glycerolysis of palm oil in an acetone/isooctane mixture $(3: 1 \mathrm{v} / \mathrm{v})$. Water was dissolved in glycerol ( $10 \% \mathrm{w} / \mathrm{v}$ of water added to glycerol) and therefore a large amount of water was present in the reaction medium. Recently, Voll et al. [17] proposed a kinetic model based on the ordered-sequential $\mathrm{Bi} \mathrm{Bi}$ mechanism for a lipase-catalyzed glycerolysis system of olive oil in TB as the solvent. In that work, the reaction products were expressed as total amount of MAG, DAG, TAG and FFA by weight percentage on a solvent-free basis composition. No experimental information on the glycerol concentration rate of change was provided. Fiametti et al. [12] used a similar model to the one proposed by Voll et al. [17] in the glycerolysis of olive oil by ultrasound irradiation. However, the parameters were not provided in the open literature although they could be available upon request to the authors.

In this work, a similar approach to that previously proposed by Moquin et al. [9] was used. The kinetic parameters were compared when possible with previous values reported in the literature. This model was able to consider the concentration of all the compounds involved in the glycerolysis system: TAG, DAG, MAG, FFA, glycerol and water.

\section{Experimental}

\subsection{Materials}

Refined sardine oil was kindly provided by Industrias Afines S.L. (Spain) with a water content of $0.19 \pm 0.03 \%$. Glycerol was purchased from Sigma Aldrich with a purity of $\geq 99.5 \%$ and a water content of $0.18 \pm 0.04 \%$. TB was purchased from Merck with a purity of $\geq 99 \%$ and a water content of $0.20 \pm 0.03 \%$. The products were stored over activated $3 \AA$ A molecular sieve to keep them dry. The food grade lipase Lipozyme ${ }^{\circledR} 435$ from Candida antarctica (immobilized on a macroporous hydrophobic acrylic resin) was donated by Novozymes A/S (Bagsvaerd, Denmark). The water content of this lipase was $3.5 \pm 0.3 \%$ as determined in triplicate by Karl-Fisher titration with a Mitsubishi CA-20 moisture meter. According to Novozymes $\mathrm{A} / \mathrm{S}$, the specific activity of the lipase is $\geq 8000$ propyl laurate units/g. No additional water was added to the system. Therefore, water present in the reaction medium came only from the reactants.

\subsection{Enzymatic glycerolysis of sardine oil}

Different vials containing a mixture of sardine oil, glycerol and TB were incubated at different temperatures from 303 to $333 \mathrm{~K}$ in a water bath with stirring. Different molar ratios of substrate and enzyme dosage were also studied. The amount of TB added was fixed at a mass ratio of 1.5:1 (TB:substrates) on the basis of previous studies on LLE [13]. At selected time intervals (from $5 \mathrm{~min}$ up to $8 \mathrm{~h}$ ), a sample of the reaction mixture was withdrawn and filtered through a microfilter $(0.45 \mu \mathrm{m}$, Sartorius RC) to stop the reaction by removing the lipase. All samples were stored at $255 \mathrm{~K}$ prior to analysis.

The reusability of Lipozyme ${ }^{\circledR} 435$ in this process was tested by recycling the immobilized enzyme in six batches. After each run, the lipase was washed once with $\mathrm{TB}$, and then twice with hexane in order to eliminate the remaining compounds. Afterwards, the lipase was dried at $303 \mathrm{~K}$ and stored in a desiccator under vacuum. No significant reduction in enzyme activity was found. Anyway, a fresh biocatalyst was used in each run.

TB was evaporated under vacuum using a rotary evaporator (Heibolph VV2000) at $333 \mathrm{~K}$. This way, TB can be reused by 
using the molecular sieve to eliminate the water content.

\subsection{Analysis of the reaction products}

The neutral lipid profile (TAG, DAG, MAG and FFA) was analyzed by a normal phase high performance liquid chromatography (NP-HPLC). The chromatographic apparatus consisted of a HPLC system (Agilent 1200) formed by a quaternary pump and an auto-injector. The chromatographic separation of the compounds was carried out at room temperature with a Lichrospher Diol column (5 $\mu \mathrm{m}, 4 \mathrm{~mm} \times 250 \mathrm{~mm}$ ) and detection was performed by an evaporative light scattering detector (Agilent 1200 series) at $308 \mathrm{~K}$ and $0.35 \mathrm{MPa}$. Gradient elution was achieved by mobile phases A (isooctane) and B (methyl tert-butyl ether:acetic acid $=99.9: 0.1, v / v$ ). The method and calibration procedure were previously reported [23]. The regioisomers of DAG and MAG could not be distinguished by the applied analytical procedure. Therefore the total amount of MAG and DAG was reported for the kinetic experiments.

The analysis of the remaining glycerol was performed by a high temperature gas chromatograph (HT-GC) system (HP 6890 Series GC System) equipped with a flame ionization detector (FID), a fused silica capillary column of $30 \mathrm{~m} \times 0.25 \mathrm{~mm}$ i.d. coated with a $0.25-\mu \mathrm{m}$ film thickness of $65 \%$ phenyl methylpolisiloxane (65HT) as the stationary phase and an Agilent Technologies 7683B Series automatic injector. The method and calibration procedure were previously reported [13].

\subsection{Kinetic modeling}

The overall glycerolysis reaction can be described by:

$$
\mathrm{TAG}+2 \mathrm{Gly} \rightleftarrows 3 \mathrm{MAG}
$$

However, glycerolysis is believed to follow a two-step reaction. First, one molecule of glycerol reacts with one molecule of TAG to yield one molecule of DAG and another molecule of MAG. The reaction of one molecule of DAG with one molecule of glycerol can also take place to yield two molecules of MAG:

$$
\begin{gathered}
\mathrm{TAG}+\text { Gly } \underset{k_{2}}{\stackrel{k_{1}}{\rightleftarrows}} \mathrm{DAG}+\mathrm{MAG} \\
\mathrm{DAG}+\mathrm{Gly} \underset{k_{4}}{\stackrel{k_{3}}{\rightleftarrows}} 2 \mathrm{MAG}
\end{gathered}
$$

The breakdown of TAG due to reaction with MAG can also occur to produce two molecules of DAG [9]:

$$
\mathrm{TAG}+\mathrm{MAG} \underset{k_{6}}{\stackrel{k_{5}}{\leftrightarrows}} 2 \mathrm{DAG}
$$

Even in the presence of small amounts of water in the glycerolysis reaction medium, unwanted hydrolysis reactions must be considered:

$$
\begin{aligned}
& \mathrm{TAG}+\mathrm{H}_{2} \mathrm{O} \underset{k_{8}}{\stackrel{k_{7}}{\rightleftarrows}} \mathrm{DAG}+\mathrm{FFA} \\
& \mathrm{DAG}+\mathrm{H}_{2} \mathrm{O} \underset{k_{10}}{\stackrel{k_{9}}{\rightleftarrows}} \mathrm{MAG}+\mathrm{FFA} \\
& \mathrm{MAG}+\mathrm{H}_{2} \mathrm{O} \underset{k_{12}}{\stackrel{k_{11}}{\rightleftarrows}} \mathrm{Gly}+\mathrm{FFA}
\end{aligned}
$$

Kinetic models are needed to predict and simulate the reaction. By formulating the mass balance equation for all the species of the reaction system, the concentration profile versus time can be obtained. In this way, the process can be optimized. The rate of change in concentration for each of the reaction components are described by the following differential equations:

$$
\begin{aligned}
& \frac{\mathrm{d} n_{\mathrm{TAG}} / n_{\text {total }}}{\mathrm{d} t}=-k_{1} x_{\mathrm{TAG}} x_{\mathrm{Gly}}+k_{2} x_{\mathrm{DAG}} x_{\mathrm{MAG}}-k_{5} x_{\mathrm{TAG}} x_{\mathrm{MAG}}+ \\
& k_{6}\left(x_{\mathrm{DAG}}\right)^{2}-k_{7} x_{\mathrm{TAG}} x_{\mathrm{H}_{2} \mathrm{O}}+k_{8} x_{\mathrm{DAG}} x_{\mathrm{FFA}} \\
& \frac{\mathrm{d} n_{\mathrm{DAG}} / n_{\text {total }}}{\mathrm{d} t}=k_{1} x_{\mathrm{TAG}} x_{\mathrm{Gly}}-k_{2} x_{\mathrm{DAG}} x_{\mathrm{MAG}}-k_{3} x_{\mathrm{DAG}} x_{\mathrm{Gly}}+k_{4}\left(x_{\mathrm{MAG}}\right)^{2}+2 k_{5} x_{\mathrm{TAG}} x_{\mathrm{MAG}} \\
& -2 k_{6}\left(x_{\mathrm{DAG}}\right)^{2}+k_{7} x_{\mathrm{TAG}} x_{\mathrm{H}_{2} \mathrm{O}}-k_{8} x_{\mathrm{DAG}} x_{\mathrm{FFA}}-k_{9} x_{\mathrm{DAG}} x_{\mathrm{H}_{2} \mathrm{O}}+k_{10} x_{\mathrm{MAG}} x_{\mathrm{FFA}} \\
& \frac{\mathrm{d} n_{\text {MAG }} / n_{\text {total }}}{\mathrm{d} t}=k_{1} x_{\text {TAG }} x_{\text {Gly }}-k_{2} x_{\text {DAG }} x_{\text {MAG }}+2 k_{3} x_{\text {DAG }} x_{\text {Gly }}-2 k_{4}\left(x_{\text {MAG }}\right)^{2} \\
& -k_{5} x_{T A G} x_{\text {MAG }}+k_{6}\left(x_{\mathrm{DAG}}\right)^{2}+k_{9} x_{\mathrm{DAG}} x_{\mathrm{H}_{2} \mathrm{O}} \\
& -k_{10} x_{\mathrm{MAG}} x_{\mathrm{FFA}}-k_{11} x_{\mathrm{MAG}} x_{\mathrm{H}_{2} 0}+k_{12} x_{\mathrm{Gly}} x_{\mathrm{FFA}} \\
& \frac{\mathrm{d} n_{\mathrm{Gly}} / n_{\mathrm{total}}}{\mathrm{d} t}=-k_{1} x_{\mathrm{TAG}} x_{\mathrm{Gly}}+k_{2} x_{\mathrm{DAG}} x_{\mathrm{MAG}}-k_{3} x_{\mathrm{DAG}} x_{\mathrm{Gly}} \\
& +k_{4}\left(x_{\mathrm{MAG}}\right)^{2}+k_{11} x_{\mathrm{MAG}} x_{\mathrm{H}_{2} \mathrm{O}}-k_{12} x_{\mathrm{Gly}} x_{\mathrm{FFA}} \\
& \frac{\mathrm{d} n_{\mathrm{FFA}} / n_{\mathrm{total}}}{\mathrm{d} t}=k_{7} x_{\mathrm{TAG}} x_{\mathrm{H}_{2} \mathrm{O}}-k_{8} x_{\mathrm{DAG}} x_{\mathrm{FFA}}+k_{9} x_{\mathrm{DAG}} x_{\mathrm{H}_{2} \mathrm{O}} \\
& -k_{10} x_{\mathrm{MAG}} x_{\mathrm{FFA}}+k_{11} x_{\mathrm{MAG}} x_{\mathrm{H}_{2} \mathrm{O}}-k_{12} x_{\mathrm{Gly}} x_{\mathrm{FFA}} \\
& \frac{\mathrm{d} n_{\mathrm{H}_{2} \mathrm{O}} / n_{\text {total }}}{\mathrm{d} t}=-k_{7} x_{\mathrm{TAG}} x_{\mathrm{H}_{2} \mathrm{O}}+k_{8} x_{\mathrm{DAG}} x_{\mathrm{FFA}}-k_{9} x_{\mathrm{DAG}} x_{\mathrm{H}_{2} \mathrm{O}} \\
& +k_{10} x_{\mathrm{MAG}} x_{\mathrm{FFA}}-k_{11} x_{\mathrm{MAG}} x_{\mathrm{H}_{2} \mathrm{O}}+k_{12} x_{\mathrm{Gly}} x_{\mathrm{FFA}}
\end{aligned}
$$

As explained above in the analytical procedure, the stereoisomers of DAG and MAG could not be distinguished and no difference was made between them in the model. The concentrations of the reaction products were expressed on a solvent-free basis. TAG, DAG, MAG, FFA and glycerol concentrations were experimentally determined. The water concentration could not be experimentally determined. According to Moquin et al. [9], it is possible to estimate the change in water concentration by subtracting the experimental FFA concentration from the initial water concentration since the formation of one mole FFA requires one mole of water (Eqs. (5)-(7)).

The rate constants for the six kinetic equations were obtained by solving the set of differential equations simultaneously. The differential equations were solved numerically with a fourth order Runge-Kutta method and the parameters were obtained by minimizing the following objective function (O.F.) using the simplex Nelder-Mead method.

$$
\text { O. F. }=\frac{\sum_{\text {all samples }} \sum_{i=1}^{n}\left(x_{i, \text { exp }}-x_{i, \text { calc }}\right)^{2}}{n_{\text {samples }}} \cdot 100
$$

where the subscript " $i$ " refers to the different components in the glycerolysis system: TAG, DAG, MAG, FFA, glycerol and water. The subscripts "exp" and "calc" refer to the experimental and calculated mole fraction of the different components for each experimental kinetic data point ( $\left.n_{\text {samples}}\right)$, respectively.

The root mean square deviation (rmsd) was calculated to evaluate the quality of the fitting:

$$
\text { rmsd }=\sqrt{\frac{\sum_{i=1}^{\mathrm{NOBS}}\left(w_{i}^{\text {exp }}-w_{i}^{\mathrm{calc}}\right)^{2}}{\mathrm{NOBS}}}
$$

where NOBS is the total number of kinetic data points for all the kinetic experiments and $w_{i} \exp$ and $w_{i}$ calc are the experimental and calculated weight fractions for the reaction compounds, respectively.

\section{Results and discussion}

\subsection{Mass transfer analysis}

External and intraparticle mass transfer resistance can influence the observed reaction rate in heterogeneous catalytic processes such as immobilized lipase biocatalysis. Before the 
Table 1

Initial rate of MAG formation as a function of stirring speed $(T=303.15$ $\mathrm{K}, 2.5 \%$ enzyme loading based on substrate weight, molar ratio $\mathrm{MR}=$ 3:1) and viscosity of reaction components.

\begin{tabular}{lcc}
\hline Orbital speed $(\mathrm{r} / \mathrm{min})$ & \multicolumn{2}{c}{$r_{\mathrm{o}}(\mathrm{mmol} /(\mathrm{L} \cdot \mathrm{min}))$} \\
\hline 120 & \multicolumn{2}{c}{$0.7 \pm 0.1$} \\
170 & \multicolumn{2}{c}{$0.8 \pm 0.2$} \\
200 & \multicolumn{2}{c}{$0.8 \pm 0.1$} \\
\hline \multirow{2}{*}{ Compound } & \multicolumn{2}{c}{ Viscosity $(\mathrm{mPa} \cdot \mathrm{s})$} \\
\cline { 2 - 3 } & $303 \mathrm{~K}$ & $323 \mathrm{~K}$ \\
\hline Glycerol [34] & 612 & 142 \\
Fish oil [35] & $60-90^{*}$ & $20-30$ \\
Tert-butanol [36] & 3.392 & 1.421 \\
\hline Fy
\end{tabular}

*Value at $298.15 \mathrm{~K}$.

study of the effect of the kinetic variables, the mass transfer rate was analyzed.

TB was used as the organic solvent to provide an environment where oil and glycerol can interact since both reactants are completely immiscible. TB helps to create a homogeneous phase and also decreases the viscosity of the reaction medium since both reactants are highly viscous, especially glycerol (Table 1). To evaluate the external mass transfer resistance, the glycerolysis reaction was carried out at different orbital speeds, from 120 to $200 \mathrm{rpm}$, while keeping constant the rest of the reaction conditions. The results are presented in Table 1. From these results, it can be concluded that there was no increase in the initial reaction rate of MAG formation in the speed range studied. This result was expected since external diffusion does not usually control the overall rate unless the stirring speed is very low or the reaction mixture is very viscous [24]. TB helps to decrease the viscosity of the reaction medium since its viscosity is more than 100 smaller than the viscosity of glycerol (Table 1), resulting in a low external mass transfer resistance and it acts as an inert carrier for the reactants to the active site of the enzyme. Hence, $170 \mathrm{rpm}$ was chosen for all the glycerolysis reactions.

Slow intraparticle diffusion can reduce the overall reaction rate, especially if the reactant molecules are large [25] and have a low mobility in the lipase support. Chesterfield et al. [26] analyzed the relative magnitude of the external liquid mass transfer resistance to the combined internal resistances (intraparticle diffusion and reaction resistances) in the ethanolysis of waste cooking oil using Novozym 435 by plotting the reciprocal initial reaction rate $\left(1 / r_{0}\right)$ as a function of inverse lipase loading $(1 / \mathrm{m})$. This plot should be a straight line, with a slope proportional to the combined internal resistances, and the intercept is proportional to the interphase mass transfer resistance. Fig. 1 illustrates this linear dependence in the glycerolysis of sardine oil. The linear fit proved that the rate controlling step is the combined internal resistances since the intercept can be considered negligible.

To evaluate the intraparticle diffusion effect, the lipase Lipozyme $^{\circledR} 435$ was separated into two fractions by a $400-\mu \mathrm{m}$ sieve ( $46 \mathrm{wt} \%$ of Lipozyme ${ }^{\circledR} 435$ particles with $\phi_{\mathrm{p}}>400 \mu \mathrm{m}$ ). Kinetic experiments were carried out with each of the fractions obtained and compared with the results obtained with unsieved lipase. Fig. 2 shows that the initial reaction rate of MAG

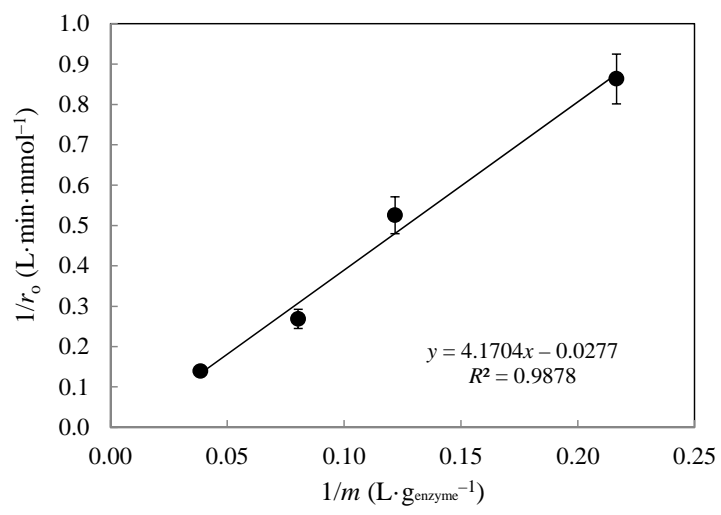

Fig. 1. Effect of catalyst loading on initial reaction rate of MAG formation $(T=323 \mathrm{~K}, \mathrm{MR}=3: 1)$.

formation was increased by decreasing the particle size of Lipozyme $^{\circledR}$ 435. This may indicate internal mass transfer limitation for the larger particles, although the same MAG yield was achieved at long reaction time. A significant pore diffusion resistance was also found by Chesterfield et al. [26] in the ethanolysis study with Novozym 435 (technical grade of Candida antartica).

The experimental Thiele modulus, $\phi_{\text {exp, was calculated to }}$ evaluate the intraparticle resistance [27]:

$$
\phi_{\text {exp }}=\left(\frac{d_{\mathrm{p}}}{6}\right)^{2} \frac{r_{\text {exp }, \text { substrate }}}{D_{\text {eff }} C_{\text {substrate }, 0}}
$$

where $d_{\mathrm{p}}$ is the mean particle diameter of Lipozyme ${ }^{\circledR} 435\left(d_{\mathrm{p}}=\right.$ $383 \mu \mathrm{m}$, [26]). The effective diffusivity, $D_{\text {eff, was evaluated using }}$ [28]:

$$
D_{\text {eff }}=\frac{D_{\text {substrate }- \text { solvent }} \varepsilon_{\mathrm{p}} \sigma}{\tau}
$$

where $\varepsilon_{\mathrm{p}}, \tau$ and $\sigma$ are Lipozyme ${ }^{\circledR} 435$ porosity, tortuosity, and constriction factor, respectively. These values were taken from Chesterfield et al. [26] for Novozym $435\left(\varepsilon_{\mathrm{p}}=0.5, \tau=6\right.$ and $\sigma=$ 1). $D_{\text {substrate-solvent is the molecular diffusivity of the reactants }}$ (glycerol and fish oil) in the reaction medium (TB in this work). It was estimated using the Wilke-Chang equation [29]:

$$
D_{\text {substrate-solvent }}=\frac{7.4 \cdot 10^{-8} T\left(M_{\text {substrate }} \psi_{\text {solvent }}\right)}{\eta_{\text {solvent }} V_{\text {substrate }}^{0.6}}
$$

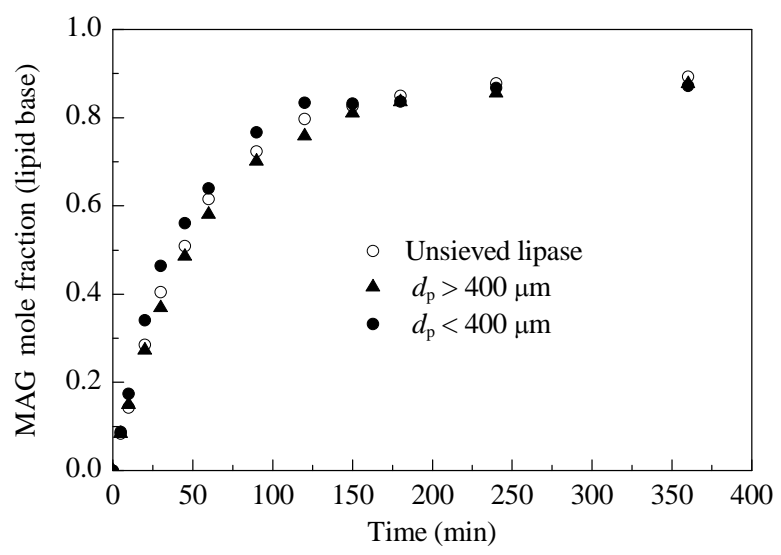

Fig. 2. Effect of particle size on MAG formation reactions. $T=323 \mathrm{~K}, 5$ wt $\%$ Lipozyme ${ }^{\circledR} 435$ loading, MR $=3: 1$, standard uncertainty $u$ (mole fraction) $=0.02$. 
where $D_{\text {substrate-solvent }}$ is the diffusion coefficient of the substrate in the solvent $\left(\mathrm{cm}^{2} / \mathrm{s}\right), M_{\text {substrate }}$ is the molecular weight of the solvent $(\mathrm{g} / \mathrm{mol}), T$ is the temperature $(\mathrm{K}), \eta_{\text {solvent }}$ is the viscosity of the solvent (cP), $V_{\text {sustrate }}$ is the molar volume of the substrate at its normal boiling temperature $\left(\mathrm{cm}^{3} / \mathrm{mol}\right)$, and $\psi$ is the association factor of the solvent (dimensionless, $\psi=1$ for non-associated compounds). The molar volume values used in the calculation of $\Phi$ are listed in Table 2. Molar volumes at the normal boiling point were estimated by the Tyn and Calus method [29]:

$$
V=0.285 V_{\mathrm{c}}^{1.048}
$$

where $V_{\mathrm{c}}$ is the critical volume in $\mathrm{cm}^{3} / \mathrm{mol}$. $V_{\mathrm{c}}$ for glycerol was $255 \mathrm{~cm}^{3} / \mathrm{mol}$ [29]. No data of $V_{c}$ for fish oil was found in the literature. The corresponding estimated value for triolein $\left(V_{c}=\right.$ $3235.65 \mathrm{~cm}^{3} / \mathrm{mol}$ ) was used [30]. $\Phi$ was evaluated for both substrates, glycerol and sardine oil, at $323 \mathrm{~K}$ for $r_{\text {exp,glycerol }=}$ $0.0173 \mathrm{mmol} /(\mathrm{L} \cdot \mathrm{s}), C_{\text {glycerol }, \mathrm{o}}=47.5 \mathrm{mmol} / \mathrm{L}, r_{\text {exp, fish oil }}=0.023$ $\mathrm{mmol} /(\mathrm{L} \cdot \mathrm{s}), C_{\text {fish oil,o }}=47.5 \mathrm{mmol} / \mathrm{L}$.

According to Bailey [31], when $\Phi$ is sufficiently large ( $\Phi \geq 3$ ), diffusion of substrate is slow relative to its consumption. When $\Phi<0.3$ the limiting rate process is the chemical reaction. $\Phi$ for diffusion of glycerol in the reaction medium was found to be 0.019 . However, a value of 0.36 was obtained for the diffusion of fish oil in TB, probably due to the bigger oil molecules that can lead to more diffusional limitation (Table 2). In any case, the value of $\Phi$ was close to the limit of 0.3 and the observed rate can be considered kinetically controlled. Based on the $\Phi$ values, the lipase was used in its commercially available size without sieving for further kinetic experiments.

Yang et al. [20] studied the effect of the loading of Novozym

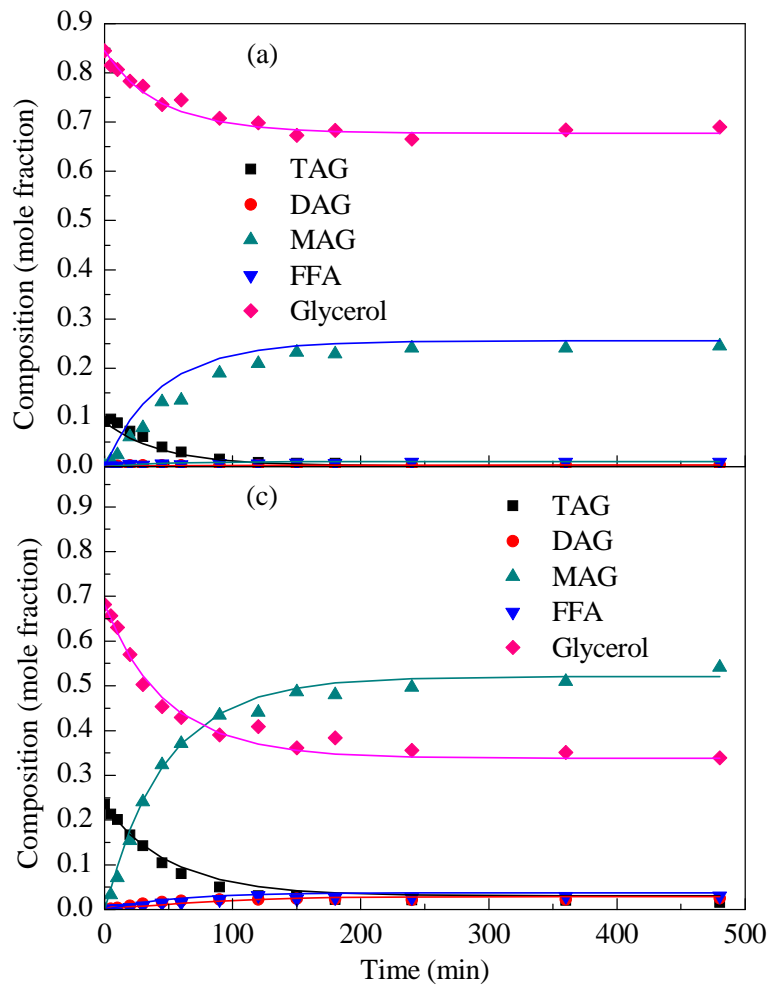

Table 2

Thiele modulus and parameter values used in its calculation.

\begin{tabular}{lc}
\hline Parameter & Value \\
\hline$V_{\text {glycerol }}$ & $94.82 \mathrm{~cm}^{3} / \mathrm{mol}$ \\
$V_{\text {fish oil } \text { triolein }}$ & $1359.20 \mathrm{~cm}^{3} / \mathrm{mol}$ \\
$\Phi_{\text {glycerol }}=0.019 \pm 0.004<0.3$ & $\Phi_{\text {fish oil }}=0.35 \pm 0.09 \sim 0.3$ \\
\hline
\end{tabular}

435 on the glycerolysis of sunflower oil. They found that an enzyme loading of more than $10 \%$ resulted in only a small increase in MAG yield. Therefore, they suggested that 10\%-15\% of enzyme loading was enough to obtain the maximum reaction performance. Moreover, other authors as Valerio et al. [11] and Fiametti et al. [12] have shown that high enzyme concentrations can lead to the formation of aggregates, making the enzyme active site unavailable to the substrates. Based on this and the results shown in Fig. 1, further glycerolysis kinetics were performed with $10 \mathrm{wt} \%$ of Lipozyme ${ }^{\circledR} 435$ based on reactant weight.

\subsection{Glycerolysis reaction system}

The presence of a catalyst is necessary since it has been shown in the Ref. [16] that under $343 \mathrm{~K}$ the observed reaction rate without a catalyst is nearly zero. Fig. 3(c) shows a typical glycerolysis profile of fish oil at the molar ratio of glycerol:sardine oil of $3: 1$ at $323 \mathrm{~K}$ with $10 \%$ of lipase loading in TB (68\% of tert-butanol). The main reaction product at the above conditions was MAG (around 51\% mole percentage), but DAG and FFA production were also observed although the mole percent was around 3\% for both compounds. The initial water

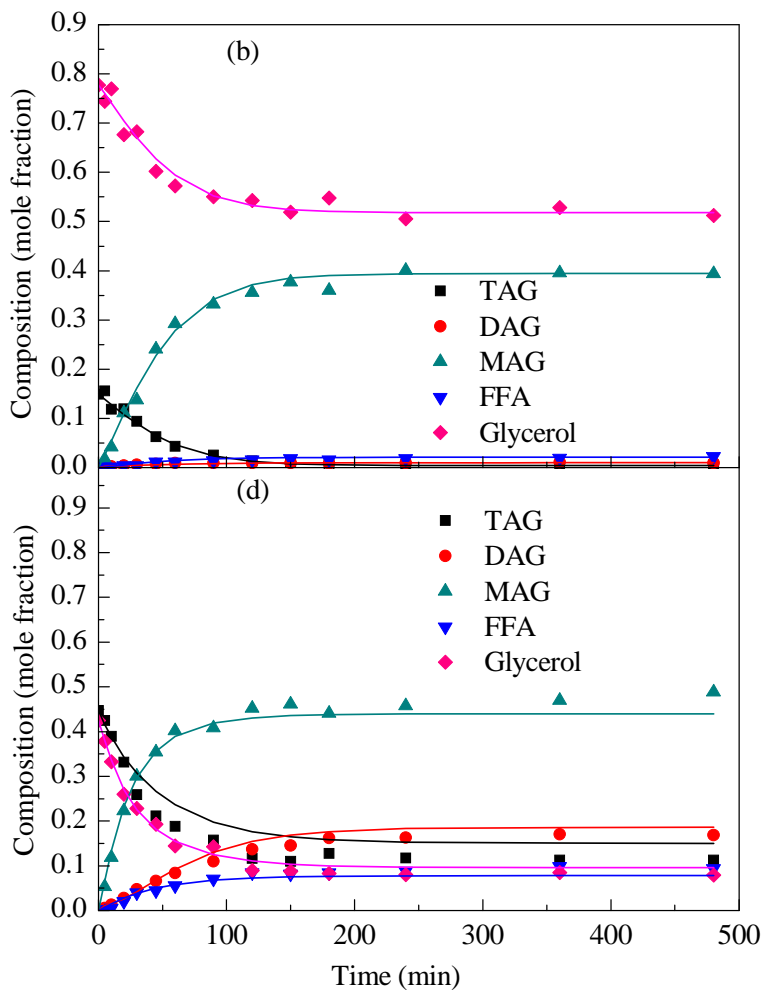

Fig. 3. Time course of the glycerolysis reaction at different molar ratios. (a) 9:1; (b) 5:1; (c) 3:1; (d) 1:1. Continuous lines are for the model proposed in this work. $323 \mathrm{~K}, 10 \mathrm{wt} \%$ Lipozyme ${ }^{\circledR} 435$ loading, standard uncertainty $u$ (mole fraction) $=0.02$. 
content in the reaction medium was less than $1 \%$ by weight but it was nearly $10 \%$ of the mole content of water in the reaction medium. Therefore FFA production can be observed. TAG consumption was nearly complete with a mole percent at equilibrium conditions lower than $2 \%$.

\subsubsection{Effect of reactant molar ratio}

The initial mole reactant ratio (MR) was varied between 1 and 9. Fig. 3(a)-(d) show the glycerolysis product profile expressed in mole fraction on a solvent-free basis. The reaction rate of formation of MAG was always higher than that of DAG and FFA. The presence of a solvent, TB, helped both reactants to diffuse to the active sites of the enzyme and MAG formation was favored. Valerio et al. [11] studied the kinetics of glycerolysis of olive oil in a surfactant system (with Triton X-100 as surfactant) as an alternative to the use of organic solvents, and found that the DAG initial reaction rate was higher than that of MAG even with an excess of glycerol (MR = 9:1). This behavior could be due to mass transfer limitation and can be compared to a situation of low glycerol concentration in the reaction medium.

The optimal MR glycerol:oil must consider the MAG yield as well as the excess of glycerol employed in the glycerolysis reaction. The equilibrium yield of MAG was calculated as:

$$
\text { Equilibrium MAG yield }(\%)=\frac{\text { Moles of MAG in the equilibrium }}{\text { Initial moles of TAG } \cdot 3} \cdot 100
$$

Fig. 4 shows that the MAG equilibrium yield remained practically constant at a MR higher than 5:1. A similar behavior was observed by Chesterfield et al. [26] in the ethanolysis of waste cottonseed cooking oil by Novozym 435. These authors proposed the following relationship for the equilibrium yield:

$$
\text { Equilibrium MAG yield (\%) }=\frac{a}{1+\exp \left(\frac{M R_{0}-M R}{b}\right)}
$$

Non-linear regression was performed by using the Marquardt algorithm (Statgraphics) giving $a=89.285$ defined as the limiting normalized MAG equilibrium [26], $b=0.922$ and $R M_{\mathrm{o}}=1.35$ with $R^{2}=0.999$.

To take into account the excess of glycerol employed, Fig. 4 also shows the MAG composition (expressed as mole percent-

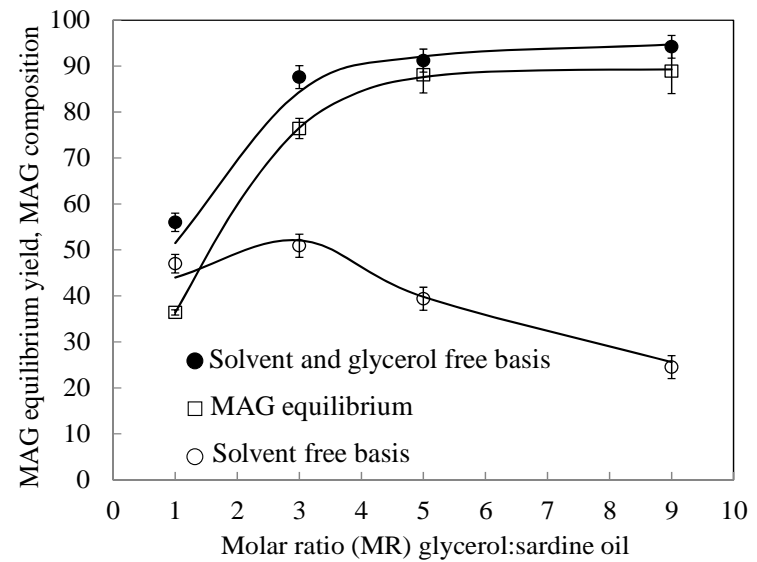

Fig. 4. MAG equilibrium yield (1) as a function of initial glycerol:oil molar ratio. The continuous line is for Eq. (20). MAG composition as mole percentage on a solvent and glycerol free-basis (2) and on a solvent free-basis (3). Continuous lines are the equilibrium composition obtained with the model in this work.

age) on a solvent-free basis and on a solvent and glycerol-free basis. In the lipid basis (no glycerol), on increasing the MR, the MAG content increased sharply from a MR of 1:0 to 3:1 and then the MAG content slightly increased in the lipid fraction. On a solvent-free basis, when glycerol was considered in the global composition, a maximum was observed in the MAG content at a MR of 3:1, due to the excess of glycerol employed that was not consumed.

Table 3 summarizes the glyceride equilibrium composition found in this work, as well as for other glycerolysis systems in the literature that use TB as solvent and immobilized Candida antarctica as the biocatalyst. The results are expressed in weight percentage on a lipid basis since in most studies, the composition was usually expressed this way. Although different lipase loadings, $E$, were used in Table 3 , the data listed in this table corresponded in most cases to equilibrium conditions and the comparison of the MAG yield can be established as valid. Table 3 shows the different results in terms of the MAG and DAG yields even at the same initial MR (as will be explained in

Table 3

Equilibrium composition of glycerolysis reaction found in this work and for other glycerolysis systems found in the literature that use TB as solvent

\begin{tabular}{|c|c|c|c|c|c|c|c|c|c|}
\hline Oil & $T(\mathrm{~K})$ & $E(\%)$ & MR & TB (\%) & MAG (\%) & DAG (\%) & TAG (\%) & FFA (\%) & Ref. \\
\hline \multirow[t]{4}{*}{ Sardine } & 323 & 10 & $1: 1$ & 63 & $43.0 \pm 1.5$ & $25.8 \pm 1.9$ & $24.6 \pm 1.5$ & $6.6 \pm 1.1$ & This work \\
\hline & & & $3: 1$ & 68 & $83.3 \pm 2.1$ & $6.9 \pm 1.1$ & $5.9 \pm 1.0$ & $3.8 \pm 1.1$ & \\
\hline & & & $5: 1$ & 68 & $89.1 \pm 1.8$ & $3.7 \pm 0.8$ & $3.0 \pm 1.0$ & $4.0 \pm 1.3$ & \\
\hline & & & $9: 1$ & 74 & $92.9 \pm 1.5$ & $2.0 \pm 0.7$ & $2.4 \pm 0.8$ & $2.8 \pm 1.1$ & \\
\hline Sunflower & 323 & 21 & $4: 1$ & 73 & 71.3 & 22.1 & 0.6 & 5.2 & [8] \\
\hline Sunflower a & 313 & 15 & $4.5: 1$ & 60 & 70 & 25 & 1 & 4 & [20] \\
\hline Tuna & 318 & 15 & $4: 1$ & 58.6 & 90.8 & 2.5 & 5.5 & 1.2 & [37] \\
\hline Camelia & 323 & 5 & $4: 1$ & 66 & $74.1 \pm 2.7$ & $24.6 \pm 0.1$ & $1.3 \pm 0.1$ & -b $^{\mathrm{b}}$ & [19] \\
\hline \multirow[t]{5}{*}{ Olive $\mathrm{a}, \mathrm{c}$} & 328 & 10 & $6: 1$ & 45 & 67 & 17 & 12 & 4 & [16] \\
\hline & 328 & 2.5 & $3: 1$ & 45 & 34 & 15 & 50 & 1 & \\
\hline & 328 & 2.5 & $3: 1$ & 80 & 42 & 19 & 36 & 3 & \\
\hline & 343 & 2.5 & $9: 1$ & 45 & 53 & 11 & 33 & 3 & \\
\hline & 343 & 2.5 & $9: 1$ & 80 & 60 & 14 & 23 & 3 & \\
\hline Olive $^{a}$ & 328 & 10 & $6: 1$ & 45 & $\sim 62$ & $\sim 19$ & $\sim 15$ & $\sim 4$ & [17] \\
\hline
\end{tabular}
and immobilized Candida antarctica as biocatalyst.

${ }^{\mathrm{a}}$ Graphical lecture; ${ }^{\mathrm{b}}$ No reference to FFA formation; ${ }^{\mathrm{c}}$ Data at $720 \mathrm{~min}$ of reaction time. 
Table 4

Composition of medium chain length fatty acids in the oils used in the glycerolysis systems listed in Table 3 .

\begin{tabular}{lcccc}
\hline \multirow{2}{*}{ Oil } & \multicolumn{3}{c}{ Medium chain length fatty acids (\%) } & \multirow{2}{*}{ Ref. } \\
\cline { 2 - 4 } & C14:0 & C16:0 & C16:1 & \\
\hline Sardine & $12.4 \pm 0.4$ & $22.8 \pm 0.2$ & $12.5 \pm 0.1$ & This work \\
Tuna & 4.2 & 30.6 & 4.7 & {$[38]$} \\
Sunflower & 0.1 & 6.7 & 0.2 & {$[8]$} \\
Olive & $0.1-1.2$ & $7.0-16.0$ & - & {$[16,17]$} \\
Camellia & - & 8.2 & - & {$[19]$} \\
\hline
\end{tabular}

Section 3.2.2, the effect of temperature on the MAG equilibrium yield was not important). For instance, at the MR glycerol:oil of $4: 1$, the MAG percentage on a lipid basis ranged from $70 \%$ for sunflower oil to $91 \%$ for tuna oil. Regarding the type of oil, fish oils gave a higher MAG yield than vegetable oils. According to the shape and properties of the scissile fatty acid binding sites of Candida antarctica lipase, in the literature, it has been reported that this lipase has high activity for short and medium chain length fatty acids [32]. Table 4 presents the fatty acid composition of the oils listed in Table 3. It can be observed that fish oils have the highest content of medium chain length fatty acids as C14:0, C16:0 and C16:1. Based on these results, a relationship between the fatty acid specificity of Candida antarctica lipase and MAG yield for the different types of oil could be established. From Table 3, it can also be observed that the amount of TB added to the system was different, ranging from $45 \%$ to $80 \%$. TB helps to create a homogeneous reaction system and avoid mass transfer limitation. Fig. 5 shows the binodal curve for the ternary system glycerol + sardine oil $+\mathrm{TB}$ at 303.15 and $323.15 \mathrm{~K}$ [13]. In this graph, the initial composition, expressed in weight fraction ( $w_{\text {glycerol, }} w_{\text {oil }}, w_{\text {tert-butanol }}$ ), of the different glycerolysis systems listed in Table 3 are also shown. Although the binodal curves can be different for the oils compared in this work, the miscibility region is expected to be of the same order. From this graph, it can be observed that in most glycerolysis systems, a homogenous phase was obtained by adding enough TB. That is, the initial glycerolysis composition lies in the one phase region. However, in both glycerolysis

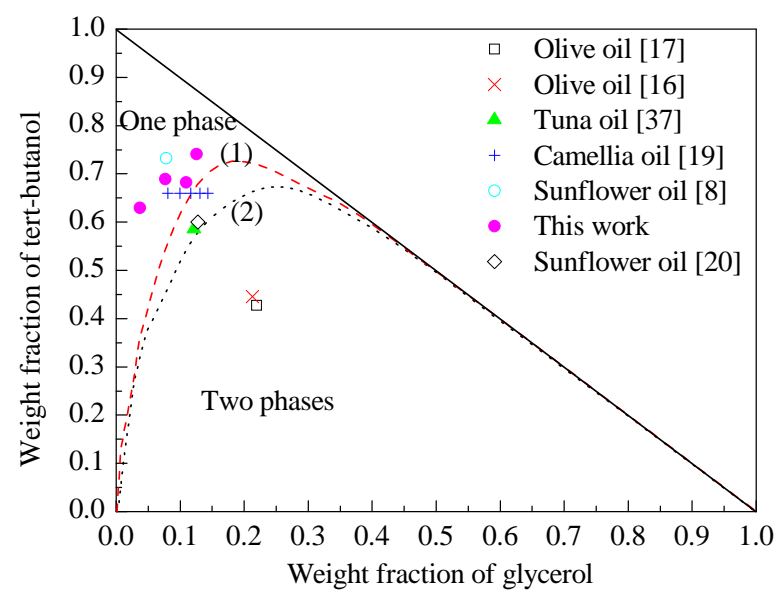

Fig. 5. Binodal curve of the ternary system glycerol + fish oil $+\mathrm{TB}$ at 303.15 (1) and 323.15 K (2). Initial composition of glycerolysis reaction in TB medium. studies for olive oil [16,17], around $45 \%$ weight percentage of TB was added to system. This amount seems to be not enough to create a homogenous phase. This can explain the low MAG yield obtained in these studies (around 65\%) compared to the other systems. In any case, MAG and DAG formed during the glycerolysis can act as emulsifier to avoid somehow mass transfer limitation. Nonetheless, in these cases, mass transfer limitation probably would only take place at the beginning of the process. Fig. 6 shows the initial reaction rates as a function of initial MR glycerol:oil . It can be observed there was an increase of the initial reaction rate for MAG and glycerol with MR up to 3. At MR larger than 3, a decrease was observed. This could be due to glycerol inhibition of the lipase-catalyzed reaction at a high MR glycerol:oil. The initial reaction rates for TAG consumption and DAG and FFA production continuously decreased on increasing the MR. According to Figs. 3 and 6, DAG production is favored by restricting the glycerol amount in the reaction medium. Similar findings were observed in other glycerolysis studies [16]. Krüger et al. [16] reported lower values for the initial reaction rates in the glycerolysis of olive oil at $328 \mathrm{~K}, 15 \mathrm{wt} \%$ of Novozym 435 and TB to substrate volume ratio of 1:1 (approximately $45 \mathrm{wt} \%$ of TB, Table 3). These authors obtained initial reaction rates of 2.136, 1.301 and 1.293 $\mathrm{mmol} / \mathrm{min}$ at MR of 3:1, 6:1 and 9:1, respectively. The low values obtained by Kruger et al. [16] compared to the values obtained in this work (Fig. 6) can be explained by assuming more mass transfer limitation at the beginning of the process due to incomplete miscibility of the reactants (Fig. 5). These authors also reported initial reaction rates for DAG production at the conditions previously detailed of $0.375,0.221$ and 0.208 $\mathrm{mmol} / \mathrm{min}$ at MR of 3:1, 6:1 and 9:1, respectively. These values are of the same order as the ones obtained in this work (Fig. 6). Finally, an optimal molar ratio of 3:1 was chosen taking into account the different effects of the amount of glycerol on the glycerolysis kinetics.

In a previous work, tert-pentanol was used as the organic solvent [15]. In that work, the effect of the glycerol:oil molar ratio on the MAG equilibrium yield and reaction rate was studied at three different values of 1:1, 3:1 and 5:1. A MAG yield up to $90 \%$ was reached at a molar ratio of $3: 1$, which was slightly

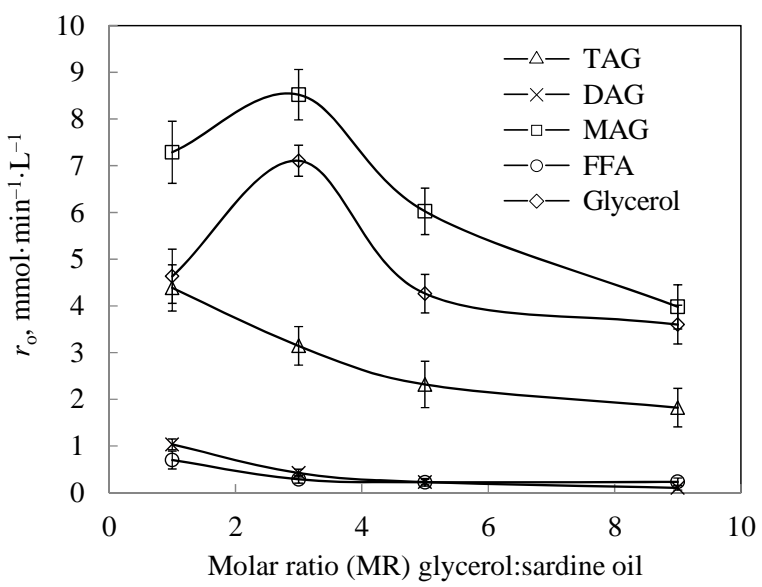

Fig. 6. Initial reaction rate as a function of initial glycerol:oil molar ratio. $323 \mathrm{~K}, 10 \mathrm{wt} \%$ Lipozyme $^{\circledR} 435$ loading. 
higher than the value found when using $\mathrm{TB}$ as the solvent (84\%). No differences in the MAG yield at a higher molar ratio could be observed for both tert-alcohols. In addition, higher initial reaction rates were observed when using tert-pentanol as the solvent. These findings can be related to the polarity of the solvents $\left(\log P_{\mathrm{TB}}=0.35\right.$ and $\left.\log P_{\mathrm{TP}}=0.85\right)$ and the hydrophobicity of the support of Lipozyme ${ }^{\circledR} 435$. Due to the higher hydrophobicity of tert-pentanol, the diffusion of reactants to the active site of the enzyme is favored.

Table 5 lists the kinetic parameters $\left(k_{1}-k_{12}\right)$ for the model used in this work and the values of the objective function for the different kinetic experiments. At the different molar ratios studied, the rate constant of the second step, $k_{3}$ (DAG to produce MAG) is larger than the first step, $k_{1}$ (TAG to DAG). Therefore, the initial breakdown of TAG is slower and it is the rate limiting step. Formation of MAG due to Eq. (4) was found to be negligible $\left(k_{6}=0\right)$, as well as hydrolysis of TAG, $k_{7}$. From the values of the model parameters, it can be concluded that the esterification rates for glycerol, $k_{12}$, MAG, $k_{10}$, and DAG, $k_{8}$, with free fatty acids followed the sequence $k_{8}<k_{10}<k_{12}$. This result was due to the steric hindrance of these groups [21]. This trend was also observed by Moquin et al. [9] in their kinetic modeling of the glycerolysis of soybean oil in supercritical carbon dioxide medium and Voll et al. [17] using an ordered-sequential Bi Bi mechanism in the glycerolysis of olive oil in TB. However, Valerio et al. [11] reported the order $k_{10}<<k_{12}<k_{8}$ for a solvent-free Novozym 435 catalyzed glycerolysis of olive oil in a surfactant system. Based on the values of the model parameters (Table 5), the production rate of MAG by esterification of glycerol, $k_{12}$, is of the same order as the production rate by the hydrolysis reaction of DAG, $k$.

It has been described that the MAG yield is favored at molar ratios larger than the stoichiometric (2:1). Voll et al. [17] pro-

\section{Table 5}

Calculated kinetic parameters at different glycerol:oil molar ratios $(T=$ $323.15 \mathrm{~K}, 10 \mathrm{wt} \%$ Lipozyme $^{\circledR} 435$ based on substrate weight). Objective function and root mean square deviation (wt\%) for the glycerolysis products.

\begin{tabular}{lcccc}
\hline Model & \multicolumn{4}{c}{ Molar ratio } \\
\cline { 2 - 5 } parameter & $1: 1$ & $3: 1$ & $5: 1$ & $9: 1$ \\
\hline$k_{1}$ & 0.0350 & 0.0264 & 0.0263 & 0.0285 \\
$k_{2}$ & 0.0023 & 0.0248 & 0.0292 & 0.0276 \\
$k_{3}$ & 0.7638 & 0.9167 & 0.9411 & 0.9411 \\
$k_{4}$ & 0.0749 & 0.0400 & 0.0348 & 0.0338 \\
$k_{5}$ & 0.0108 & 0.0096 & 0.0047 & - \\
$k_{6}$ & - & - & - & - \\
$k_{7}$ & - & - & - & - \\
$k_{8}$ & 0.0711 & 0.0046 & - & - \\
$k_{9}$ & 1.8168 & 1.9017 & 1.9022 & 1.9019 \\
$k_{10}$ & 0.4052 & 0.0234 & 0.0202 & 0.0209 \\
$k_{11}$ & 0.5853 & 0.8911 & 0.8942 & 0.8983 \\
$k_{12}$ & 1.9714 & 1.8052 & 1.8033 & 1.8008 \\
\hline O.F. & 0.0019 & 0.0013 & 0.0009 & 0.0012 \\
\hline Root mean squared deviation $($ wt $\%)$ & & \\
TAG & 4.7 & 3.4 & 5.6 & 4.6 \\
DAG & 1.0 & 0.9 & 0.4 & 0.2 \\
MAG & 3.8 & 2.7 & 5.8 & 5.6 \\
FFA & 1.1 & 0.7 & 0.5 & 0.3 \\
Glycerol & 0.4 & 1.3 & 1.7 & 2.2 \\
Water & 0.2 & 0.3 & 0.1 & 0.3 \\
\hline
\end{tabular}

posed that the most obvious hypothesis was that the excess of glycerol can react with DAG to produce 2 moles of MAG (Eq. (3)). This was reflected in the value of the $k_{3}$ parameter as a function of molar ratio. $k_{3}$ increased sharply from the MR of 1:1 to 3:1 and then remained constant, similar to the MAG equilibrium yield dependence on MR (Fig. 4). To the contrary, Voll et al. [17] found in their kinetic model that the kinetic parameter for the DAG to MAG step was negligible and attributed the increase in MAG yield with an excess of glycerol to the hydrolysis/esterification steps (Eqs. (4)-(6)). In our study, the kinetic parameter of the hydrolysis of TAG, $k_{7}$, was found negligible, although, the parameter for DAG hydrolysis, $k 9$, and esterification of FFA formed, $k_{12}$, were considerable.

The continuous lines in Fig. 3 correspond to model proposed in this work. Good agreement between experimental and calculated product concentrations can be observed.

\subsubsection{Effect of temperature}

Different kinetic experiments were carried out at different reaction temperatures from 303 to $333 \mathrm{~K}$ with an enzyme concentration of $10 \mathrm{wt} \%$ (based on substrate weight) and at the previous identified optimal glycerol:sardine oil ratio of 3:1. Fig. 7 shows the experimental kinetic data at the different reaction temperatures. The reaction rates of MAG, DAG and FFA formation as well as TAG and glycerol consumption increased by increasing the reaction temperature (initial reaction rates values at 303, 313, 323 and $333 \mathrm{~K}$ for MAG production were 2.69, 4.26, 8.16 and $9.69 \mathrm{mmol} /(\mathrm{min} \cdot \mathrm{L})$, respectively). An increase of the reaction rate by 3.0 times was obtained from 303 to $323 \mathrm{~K}$. Guo et al. [10] found an increase by 2.2 times from 303 to 323 $\mathrm{K}$, and Krüger et al. [16] by 1.8 times from 313 to $343 \mathrm{~K}$. An optimal working temperature in the range of 313-338 $\mathrm{K}$ was reported for Novozym 435 [11]. From Fig. 7, it can be also observed that the reaction temperature has only a slight effect on the equilibrium product concentrations. This behavior with temperature was also observed for other transesterification reactions [16,33].

Table 6 lists the kinetic parameters $\left(k_{1}-k_{12}\right)$ of the semi-empirical model and the values of the objective function at the different temperatures used in this work. The continuous lines in Fig. 7 correspond to the model. Good agreement can be observed between experimental and calculated product concentrations.

An Arrhenius type dependence of temperature on reaction rate was found:

$$
k_{i}=k_{i, o} \exp \left(\frac{-E_{\mathrm{act}}}{R T}\right)
$$

where $k_{i, o}$ is the preexponential factor, $E_{\text {act }}$ the activation energy and $R$ is the gas constant. Table 7 lists the activation energy calculated by fitting the kinetic reaction rate constants of Table 6 to the Arrhenius equation. The most activated steps were steps 1,2 and 5 ( $E_{\mathrm{a} 1}, E_{\mathrm{a} 2}$ and $\left.E_{\mathrm{a} 5}\right)$ that correspond to TAG consumption and reaction of DAG and MAG. The other reaction steps have small or nearly no dependence on reaction temperature. Only few activation energy data were found in the literature for the different steps in the glycerolysis process and a comparison with literature data is difficult. Guo et al. [10] re- 

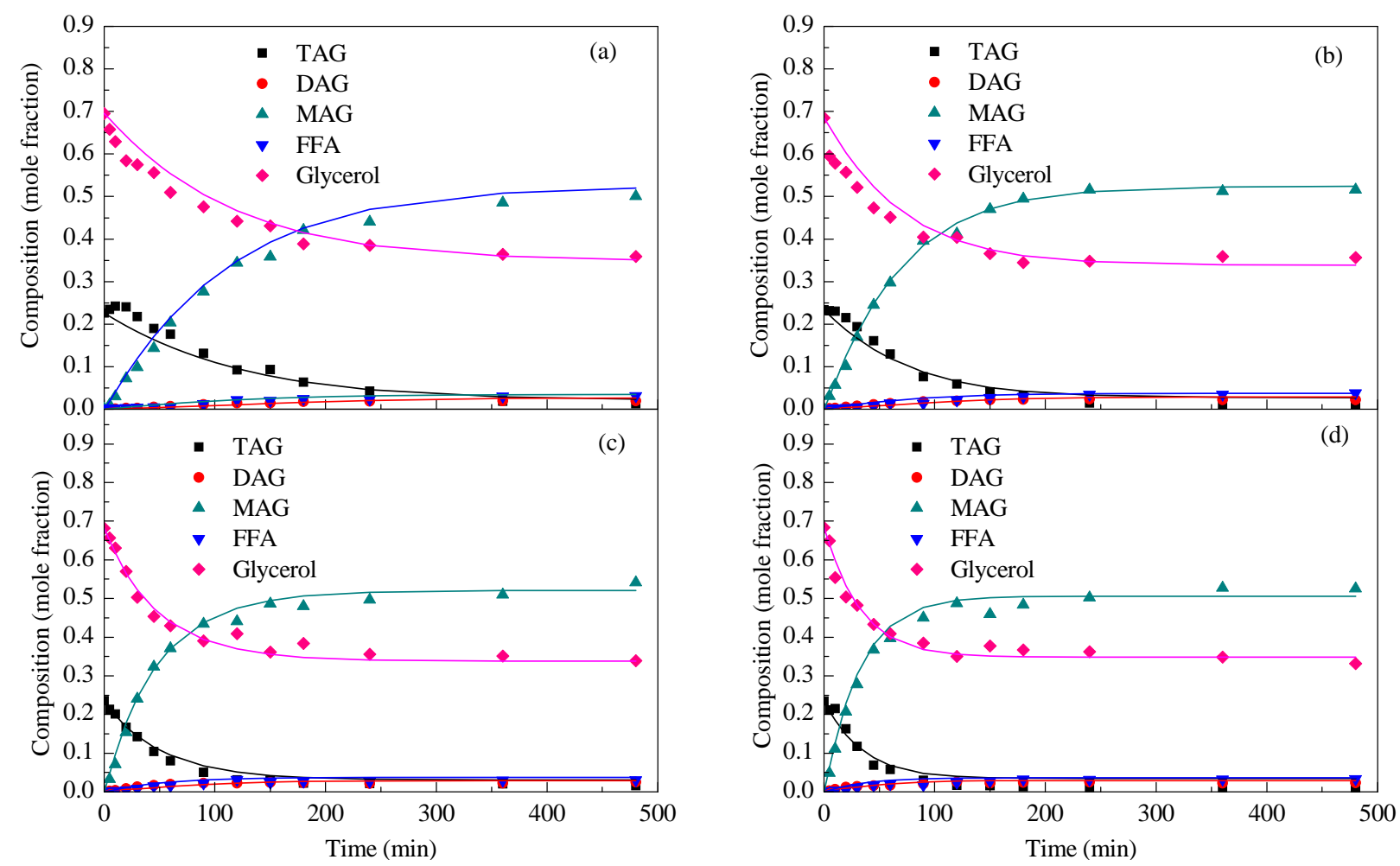

Fig. 7. Time course for the glycerolysis reaction at different temperatures. (a) $303 \mathrm{~K}$; (b) $313 \mathrm{~K}$; (c) $323 \mathrm{~K}$; (d) $333 \mathrm{~K}$. Continuous lines are for the model in this work. 10 wt $\%$ Lipozyme $^{\circledR} 435$ loading, MR $=3: 1$, standard uncertainty $u$ (mole fraction) $=0.02$.

ported a single activation energy of $33.20 \mathrm{~kJ} / \mathrm{mol}$ for MAG formation by glycerolysis of sunflower oil with Novozym 435 in TB in a temperature range of 298-328 K. This value is of the same order as the highest values listed in Table 7 for the glycerolysis steps. Table 7 also shows the activation energy values reported by Voll et al. [17] using an order sequential Bi-Bi

Table 6

Calculated kinetic parameters at different reaction temperatures (MR = 3:1, 10 wt\% Lipozyme ${ }^{\circledR} 435$ based on substrate weight). Objective function and root mean square deviation (wt\%) for the glycerolysis products.

\begin{tabular}{lcccc}
\hline Model & \multicolumn{4}{c}{ Reaction temperature (K) } \\
\cline { 2 - 5 } parameter & 303 & 313 & 323 & 333 \\
\hline$k_{1}$ & 0.0104 & 0.0164 & 0.0264 & 0.0357 \\
$k_{2}$ & 0.0106 & 0.0201 & 0.0248 & 0.0494 \\
$k_{3}$ & 0.9132 & 0.9132 & 0.9167 & 0.9194 \\
$k_{4}$ & 0.0380 & 0.0395 & 0.0400 & 0.0436 \\
$k_{5}$ & 0.0072 & 0.0114 & 0.0096 & 0.0174 \\
$k_{6}$ & - & - & - & - \\
$k_{7}$ & - & - & - & - \\
$k_{8}$ & 0.0041 & 0.0049 & 0.0046 & 0.0049 \\
$k_{9}$ & 1.9020 & 1.9017 & 1.9017 & 1.9021 \\
$k_{10}$ & 0.0207 & 0.0223 & 0.0234 & 0.0241 \\
$k_{11}$ & 0.8967 & 0.8923 & 0.8911 & 0.8970 \\
$k_{12}$ & 1.8017 & 1.8041 & 1.8052 & 1.8069 \\
\hline O.F. & 0.0027 & 0.0021 & 0.0013 & 0.0030 \\
\hline Root mean squared deviation $($ wt\% $\%)$ & & \\
TAG & 4.7 & 4.7 & 3.4 & 5.5 \\
DAG & 0.6 & 0.7 & 0.9 & 0.6 \\
MAG & 2.8 & 3.1 & 2.7 & 4.7 \\
FFA & 0.4 & 0.6 & 0.7 & 0.7 \\
Glycerol & 1.9 & 2.3 & 1.3 & 1.7 \\
Water & 0.4 & 0.2 & 0.3 & 0.3 \\
\hline
\end{tabular}

mechanism in the fitting for the glycerolysis of olive oil by Novozym 435 in TB. As can be clearly observed, a different order of activation energy is obtained for the different steps proposed, especially for the activation energy of the hydrolysis of MAG (step 11) and the reverse esterification of the free fatty acid (step 12). Table 7 also presents the activation energy values obtained by Valerio et al. [11] in the glycerolysis of olive oil by Novozym 435 in a surfactant system. A comparison of the solvent systems (TB in this case) and surfactant systems is difficult since the kinetic parameters for enzyme behavior depended strongly on the solvent medium [10]. In any case, TAG consumption by reaction with glycerol seems to be temperature dependent in all the cases shown in Table 7. Valerio et al. [11] found that the most sensitive step to temperature was the reaction of TAG with MAG $\left(E_{a, 5}\right)$ with an extremely high activation energy.

Table 8 shows the rmsd calculated from Eq. (15) for all the kinetic experiments performed in this work at different temperatures and molar ratios. The low rmsd values obtained for all the products composition, less than $5 \mathrm{wt} \%$, proved that the model fitted the glycerolysis system at the experimental conditions used. Table 8 summarized the rmsd obtained by Voll et al. [17] when correlating kinetic data to an ordered-sequential Bi Bi mechanism and the values obtained in this work. Similar values of rmsd are obtained for both models.

\section{Conclusions}

Glycerolysis of sardine oil using Lipozyme ${ }^{\circledR} 435$ was carried out at different catalyst concentrations, glycerol:oil molar ratios 
Table 7

Activation energy $(\mathrm{kJ} / \mathrm{mol})$ for the different steps in some glycerolysis systems.

\begin{tabular}{lccc}
\hline Step & $E_{\mathrm{a}, i}($ this work $)$ & $E_{\mathrm{a}, i}[17]^{\mathrm{a}}$ & $E_{\mathrm{a}, i}[11]^{\mathrm{b}}$ \\
\hline 1 & 35.18 & 18.30 & 27.91 \\
2 & 40.12 & $5.36 \times 10^{-5}$ & 0.06 \\
3 & 0.20 & - & 47.08 \\
4 & 3.52 & $1.097 \times 10^{-4}$ & $2.68 \times 10^{-12}$ \\
5 & 20.64 & $8.397 \times 10^{-4}$ & 208.17 \\
6 & - & 0.35 & 11.46 \\
7 & - & 15.55 & 62.83 \\
8 & 4.10 & - & 13.33 \\
9 & 0.001 & 2.33 & $1.11 \times 10^{-13}$ \\
10 & 4.20 & - & 69.46 \\
11 & 0.009 & 45.46 & 71.48 \\
12 & 0.08 & 15.77 & 81.77 \\
\hline
\end{tabular}

${ }^{\mathrm{a}}$ Solvent $=$ tert-butanol; ${ }^{\mathrm{b}}$ Surfactant system.

\section{Table 8}

Root mean square deviation (wt\%) for glycerolysis products obtained with our model Eqs. (1)-(6).

\begin{tabular}{lcccccc}
\hline TAG & DAG & MAG & FFA & Glycerol & Water & Ref. \\
\hline 4.74 & 0.63 & 4.02 & 0.60 & 1.65 & 0.25 & This work \\
4.19 & 2.73 & 3.58 & 1.04 & - $^{-}$ & $-\mathrm{a}$ & {$[17]$} \\
\hline
\end{tabular}

a Data not reported.

and reaction temperatures. A homogeneous phase was created by adding an optimized amount of tert-butanol based on phase equilibrium calculations. It was shown that external and internal diffusion limitation can be considered negligible and the surface reaction was the rate controlling step. A lipase loading of $10 \mathrm{wt} \%$ of unsieved Lipozyme ${ }^{\circledR} 435$ based on reactant weight was used in all kinetic experiments. A molar ratio of glycerol:oil of 3:1 was the optimum and it produced more than $84 \mathrm{wt} \%$ of MAG at $323 \mathrm{~K}$. Experimental kinetic data were successfully correlated with a kinetic model based on the reversible elementary reactions. TAG consumption by reaction with glycerol and the reverse reaction are the steps more dependent on temperature. These results agree with those for the TAG consumption in the literature. However, different kinetic parameters for most of the different steps involved in the glycerolysis system can be found in the literature and further studies are needed to be sure of the kinetic parameters of the different steps.

\section{Acknowledgments}

Thanks to the Spanish Government through MINECO (CTQ2012-39131-C02-01) for financial support. Angela García Solaesa acknowledges University of Burgos for a pre-doctoral fellowship. Rodrigo Melgosa acknowledges MINECO for a pre-doctoral grant (reference BES-2013-063937).

\section{References}

[1] E. A. M. De Deckere, O. Korver, P. M. Verschuren, M. B. Katan, Eur. J. Clin. Nutr., 1998, 52, 749-753.

[2] P. M. Kris-Etherton, W. S. Harris, L. J. Appel, Circulation, 2002, 106, 2747-2757.

[3] P. D. Nichols, A. McManus, K. Krail, A. J. Sinclair, M. Miller, Nutrients, 2014, 6, 3727-3733.

[4] E. M. Hernandez, Lipid. Technol., 2014, 26, 103-106.

[5] L. D. Lawson, B. G. Hughes, Biochem. Biophys. Res. Commun., 1988, $152,328-335$.

[6] N. J. Zhong, L. Li, X. B. Xu, L. Z. Cheong, B. Li, S. Q. Hu, X. H. Zhao, J. Am. Oil. Chem. Soc., 2009, 86, 783-789.

[7] U. T. Bornscheuer, Enzyme Microb. Technol., 1995, 17, 578-586.

[8] M. L. Damstrup, T. Jensen, F. V. Sparsø, S. Z. Kiil, A. D. Jensen, X. Xu, J. Am. Oil Chem. Soc., 2005, 82, 559-564.

[9] P. H. L. Moquin, F. Temelli, J. W. King, M. M. Palcic, J. Am. Oil Chem. Soc., 2005, 82, 613-617.

[10] Z. Guo, X. B. Xu, Green Chem., 2006, 8, 54-62.

[11] A. Valério, R. L. Krüger, J. Ninow, F. C. Corazza, D. De Oliveira, J. Vladimir Oliveira, M. L. Corazza, J. Agric. Food Chem., 2009, 57,

\section{Graphical Abstract}

Chin. J. Catal., 2016, 37: 596-606 doi: 10.1016/S1872-2067(15)61040-3

Kinetic study and kinetic parameters of lipase-catalyzed glycerolysis of sardine oil in a homogeneous medium

Ángela García Solaesa, María Teresa Sanz*, Sagrario Beltrán, Rodrigo Melgosa

University of Burgos, Spain

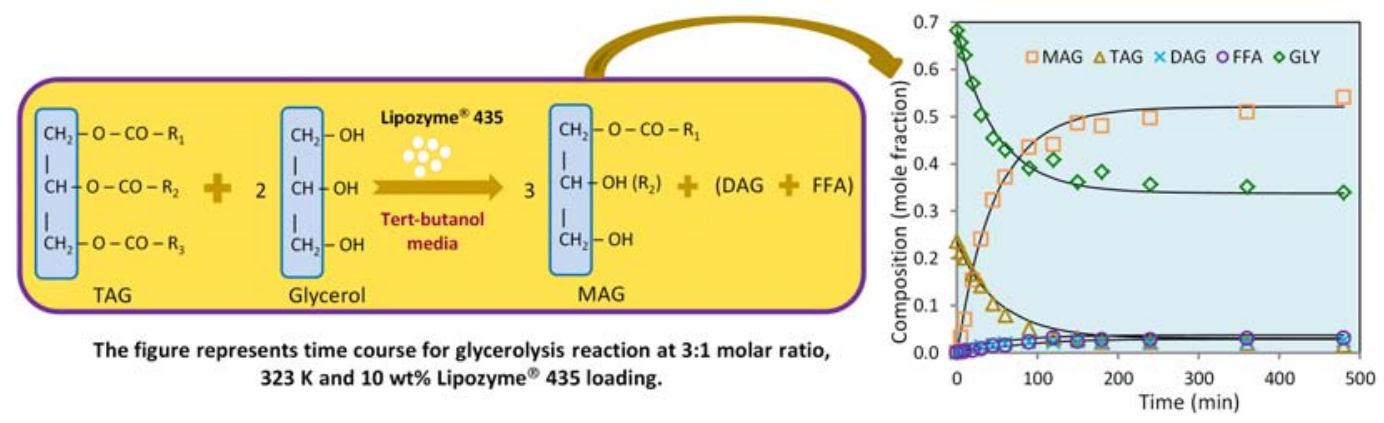

This work presents a detailed kinetic study of enzymatic glycerolysis of sardine oil catalyzed by the commercial lipase Lipozyme ${ }^{\circledR} 435$. Glycerolysis is carried out in tert-butanol to create a homogeneous system avoiding mass transfer limitations. 
8350-8356.

[12] K. G. Fiametti, M. K. Ustra, D. De Oliveira, M. L. Corazza, A. Furigo Jr, J. Vladimir Oliveira, Ultrason. Sonochem., 2012, 19, 440-451.

[13] Á. G. Solaesa, S. L. Bucio, M. T. Sanz, S. Beltrán, S. Rebolleda, Fluid Phase Equilib., 2013, 356, 284-290.

[14] M. L. Damstrup, J. Abildskov, S. Kiil, A. D. Jensen, F. V. Sparsø, X. B. $\mathrm{Xu}$, J. Agric. Food Chem., 2006, 54, 7113-7119.

[15] Á. G. Solaesa, M. T. Sanz, M. Falkeborg, S. Beltrán, Z. Guo, Food Chem., 2016, 190, 960-967.

[16] R. L. Krüger, A. Valério, M. Balen, J. L. Ninow, J. Vladimir Oliveira, D. de Oliveira, M. L. Corazza, Eur. J. Lipid Sci. Technol., 2010, 112, 921-927.

[17] F. Voll, R. L. Krüger, F. de Castilhos, L. Cardozo Filho, V. Cabral, J. Ninow, M. L. Corazza, Biochem. Eng. J., 2011, 56, 107-115.

[18] N. Majid, B. Cheirsilp, Int. J. Food Sci. Technol, 2012, 47, 793-800.

[19] F. K. Zeng, B. Yang, Y. H. Wang, W. F. Wang, Z. X. Ning, L. Li, J. Am. Oil Chem. Soc., 2010, 87, 531-537.

[20] T. Yang, M. Rebsdorf, U. Engelrud, X. B. Xu, J. Agric. Food Chem., 2005, 53, 1475-1481.

[21] T. W. Tan, C. H. Yin, Biochem. Eng. J., 2005, 25, 39-45.

[22] B. Cheirsilp, W. Kaewthong, A. H-Kittikun, Biochem. Eng. J., 2007, $35,71-80$.

[23] Á. G. Solaesa, S. L. Bucio, M. T. Sanz, S. Beltrán, S. Rebolleda, J. Oleo. Sci., 2014, 63, 449-460.

[24] M. T. Sanz, R. Murga, S. Beltrán, J. L. Cabezas, J. Coca, Ind. Eng. Chem. Res., 2002, 41, 512-517.
[25] F. G. Helfferich, Ion Exchange, McGraw-Hill, New York, 1962.

[26] D. M. Chesterfield, P. L. Rogers, E. O. Al-Zaini, A. A .Adesina, Chem. Eng. J., 2012, 207-208, 701-710.

[27] H. P. Dong, Y. J. Wang, Y. G. Zheng, J. Mol. Catal. B, 2010, 66, 90-94.

[28] H. S. Fogler, Elements of Chemical Reaction Engineering, 3rd ed, Prentice-Hall International, Inc., New Jersey, 1999.

[29] R. C. Reid, J. M. Prausnitz, B. E. Poling, The Properties of Gases \& Liquids, 4th ed, McGraw-Hill Book Company, New york, 1987.

[30] P. Olivares-Carrillo, J. Quesada-Medina, A. P. de los Ríos, F. J. Hernández-Fernández, Chem. Eng. J., 2014, 241, 418-432.

[31] J. E. Bailey, D. F. Ollis, Biochemical Engineering Fundamentals, Mcgrawhill, New York, 1986.

[32] J. Pleiss, M. Fischer, R. D. Schmid, Chem. Phys. Lipids, 1998, 93, 67-80.

[33] S. L. Bucio, Á. G. Solaesa, M. T. Sanz, R. Melgosa, S. Beltrán, H. Sovová, J. Oleo. Sci., 2015, 64, 431-441.

[34] R. J. Sengwa, V. Khatri, S. Choudhary, S. Sankhla, J. Mol. Liq., 2010, 154, 117-123.

[35] F. V. K. Young, The Chemical \& Physical Properties of Crude Fish Oils for Refiners \& Hidrogenators, Fish Oil Bulletin, 1986.

[36] F. I. Chowdhury, M. A. Saleh, J. Mol. Liq., 2014, 191, 156-160.

[37] R. Pawongrat, X. Xu, A. H-Kittikun, J. Sci. Food Agric., 2008, 88, 256-262.

[38] R. Pawongrat, X. Xu, A. H-Kittikun, Food Chem., 2007, 104, 251-258.

\title{
均相介质中脂肪酶催化沙丁鱼油甘油解反应的动力学研究
}

\author{
Ángela García Solaesa, María Teresa Sanz*, Sagrario Beltrán, Rodrigo Melgosa \\ 布尔戈斯大学生物技术与食品科学系(化学工程部), 布尔戈斯09001, 西班牙
}

摘要: 多不饱和脂肪酸(PUFAs)的生产多集中在酶催化, 与无机催化相比, 酶催化具有定向性和更温和的反应条件, 因而酶 催化制取多不饱和脂肪酸的路线在最近几年引起人们极大的兴趣. 本文以优化量的叔丁醇为有机溶剂, 研究了脂肪酶 Lipozyme $^{\circledR} 435$ 催化沙丁鱼油甘油解反应生成 PUFA (多以甘油一酯或二酯(DAGs, MAGs)的形式存在). 首先分析了反应 系统的传质影响, 考察了脂肪酶载量、温度和进料浓度等因素的影响. 采用一个基于甘油酯甘油解和水解这对可逆基元反 应的半经验动力学模型, 成功地关联了实验的动力学数据. 结果表明, 温度为 $323 \mathrm{~K}$, 甘油与油的摩尔比为 $3: 1$ 时, 生成的 MAG 可达 $84 \mathrm{wt} \%$ 以上. 还考察了其他甘油解体系, 并在 MAG 收率、反应速率和动力学参数意义等方面进行了比较.

关键词: 脂肪酶; 甘油解反应; 叔丁醇; 传质; 动力学模型

收稿日期: 2015-11-18. 接受日期: 2016-01-04. 出版日期: 2016-04-05.

*通讯联系人. 电话: +34-947-258810; 传真: +34-947-258831; 电子信箱: tersanz@ubu.es

本文的英文电子版由Elsevier出版社在ScienceDirect上出版(http://www.sciencedirect.com/science/journal/18722067). 